\title{
THE RESPONSE OF INFANTS TO A LARGE DOSE OF WATER
}

\author{
BY \\ R. A. MCCANCE, N. J. B. NAYLOR and E. M. WIDDOWSON \\ From the Medical Research Council Department of Experimental Medicine, University of Cambridge
}

(RECEIVED FOR PUBLICATION OCTOBER 30, 1953)

Whatever the mechanisms involved, the response of the adult kidney to a large dose of water has three characteristics: (1) a great increase in the flow of urine; (2) an extensive fall in its osmolar concentration; (3) the excretion of a volume of urine within a few hours and before the flow of urine subsides which is roughly equal to that of the water administered.

The ability of very young animals to regulate the amount of water in their bodies was first tested by Aschenheim (1919), Ohlmann (1920), Wengraf (1921) and Lasch (1923). The first two found that within three months of birth human infants did not excrete the whole of the test dose. This was not confirmed by Wengraf who found that the infants responded to the test dose by quickly raising the rate of urine flow and that extra-renal losses of water were large enough to account for the differences between the volume administered and that excreted by the kidney. Lasch (1923) then made a further study of the problem and concluded that in the first month of life infants only excreted an average of $55 \%$ of the test dose within four hours and that extra-renal losses were not enough to account for the remaining $45 \%$. He further observed that the formation of urine returned to its initial rate within four hours, even if the whole of the test dose had not been excreted.

Adolph (1943) investigated puppies of various ages after giving them $5 \%$ of their body weights of water. The animals absorbed all the water but at 2 days of age they excreted less than half the dose within four hours, and the normal adult response was not acquired till the animals were eight to 21 days old. The method used to follow the excretion of water included a determination of losses by the lungs and skin. Adolph stated that the slow diuresis in young puppies continued for many hours but the chart published only covers the first four after the water had been administered. McCance and Wilkinson (1947) and Heller (1947, 1951) studied the response of the newborn rat to a test dose of water. This animal is less mature in many respects than the human infant at birth, and although the test dose was absorbed, this was not followed by any significant diuresis or fall in osmolar concentration of the urine. Little of it was excreted within the period of observation. The guinea-pig is more mature at birth than the rat, and Dicker and Heller (1951) found that the newborn of this species (see also Heller, 1951) responded to the test dose by a diuresis, but that the rate of flow never equalled that of the adult animals per unit of body weight and it subsided when little more than half the volume administered had been excreted by the kidneys. The authors did not make a special study of the extrarenal losses but their experience with the rat led them to conclude that these losses could not account for the difference (Heller, personal communication).

Barnett, Vesterdal, McNamara and Lauson (1952) took up some of these questions in premature infants, and found that, contrary to general opinion based upon animal experiments, the premature infant was fully as capable of lowering the osmotic pressure of its urine as an adult, although the minute volumes achieved during the diuresis were not equal to those of adults per unit of surface area. They attributed this to the low glomerular filtration rates in the premature infants. Ames (1953) established the importance of age in the human species by giving $3 \%$ of the body weight of water to groups of infants, some of whom were less than 24 hours old and others up to 3 months. The percentage of the dose excreted within three hours rose from $10 \%$ in the first 24 hours of life to about $55 \%$ at the end of the first week and $100 \%$ before the end of the first month.

The present investigations were undertaken some years ago (McCance and Naylor, 1952) to supplement the knowledge then in existence about the excretion of water by newborn animals. The adults and infants have been compared with respect to the three characteristics outlined above. 
Subjects and Procedure

Ten normal babies (five boys and five girls) and seven healthy adults (six men and one woman) have been the main subjects for this investigation. The adults were tested after an overnight fast. They lay down on reaching the laboratory and only got up during the test to pass urine. They were not catheterized. After preliminary samples of urine and blood had been collected the subjects drank the test dose of water as quickly as possible and emptied their bladders at appropriate intervals over the next four hours. Additional samples of blood were sometimes taken. The dose of water administered was $5 \%$ of the weight of the body or approximately $6 \%$ of the weight of water in the body. Three other adults who were tested had to be rejected from the main series because they were unable to take all the water or subsequently vomited part of it. The results obtained on them have, however, been included in Fig. 3.

The 10 babies were aged 6 to 18 days. They were fed at 2 a.m. on the day of the test but not at 6 a.m. The test began between 8 and 10 a.m. A catheter was inserted and the bladder emptied. Urine was then collected for approximately one hour, and the test dose of water, again equivalent to $5 \%$ of the body weight, was administered by stomach tube. Thereafter the bladder was emptied at appropriate intervals for the next four hours. In five babies no samples of blood were taken and in five a sample was withdrawn after the diuresis had subsided. Only two of the babies were being breast fed. (Permission to make experiments has always been obtained from the mother of any infant investigated.)

Tests were made on five other babies, aged 6 to 39 days, who had been born with inoperable meningo-myelocoeles. These babies were given no food or water after midnight preceding the test. A catheter was inserted about 8 a.m. and the bladder emptied. A preliminary sample of blood was taken and urine collected for about an hour, then $15-20 \mathrm{ml}$. of a $10 \%$ solution of inulin was given subcutaneously, and after another hour a sample of blood was taken, the bladder again emptied and the test dose of water administered by stomach tube. Thereafter the bladder was emptied at intervals as for normal babies, and blood was taken at the height of the diuresis. This procedure proved unsuitable for part of the research in hand because the removal of the blood samples almost always interrupted the natural rise and fall of the flow of urine.

Vesterdal and Tudvad (1949) reported that painful injections caused a large fall in the inulin and para-amino hippurate clearances. They interpreted these results as being due to constriction of the vasa afferentia. In agreement with this Barnett and Vesterdal (1953) found that the fall in volume which followed painful stimuli was not accompanied by an increase in the concentration of urinary solids. Verney (1946), however, found that emotional upsets reduced the volume of urine in dogs by provoking a secretion of post-pituitary hormone and the results of Ames (1953) indicate that the same mechanism operates in human infants. Brod (1953) has reviewed the subject in an interesting and general way, and it is now certain that the responses to emotion may be very variable and may even lead to a diuresis (Miles and De Wardener, 1953).

Fig. 1 shows results obtained in one baby in the course of this investigation. The fall in volume was accompanied by a corresponding rise in the osmotic pressure of the urine. This indicates strongly that the response was due to an increased secretion of post-pituitary hormone and the time relationship of the fall to the stimulus is in agreement with this.

\section{Chemical and Analytical Methods}

All urines were stored under toluol. When blood was taken the sample was collected without anticoagulant and

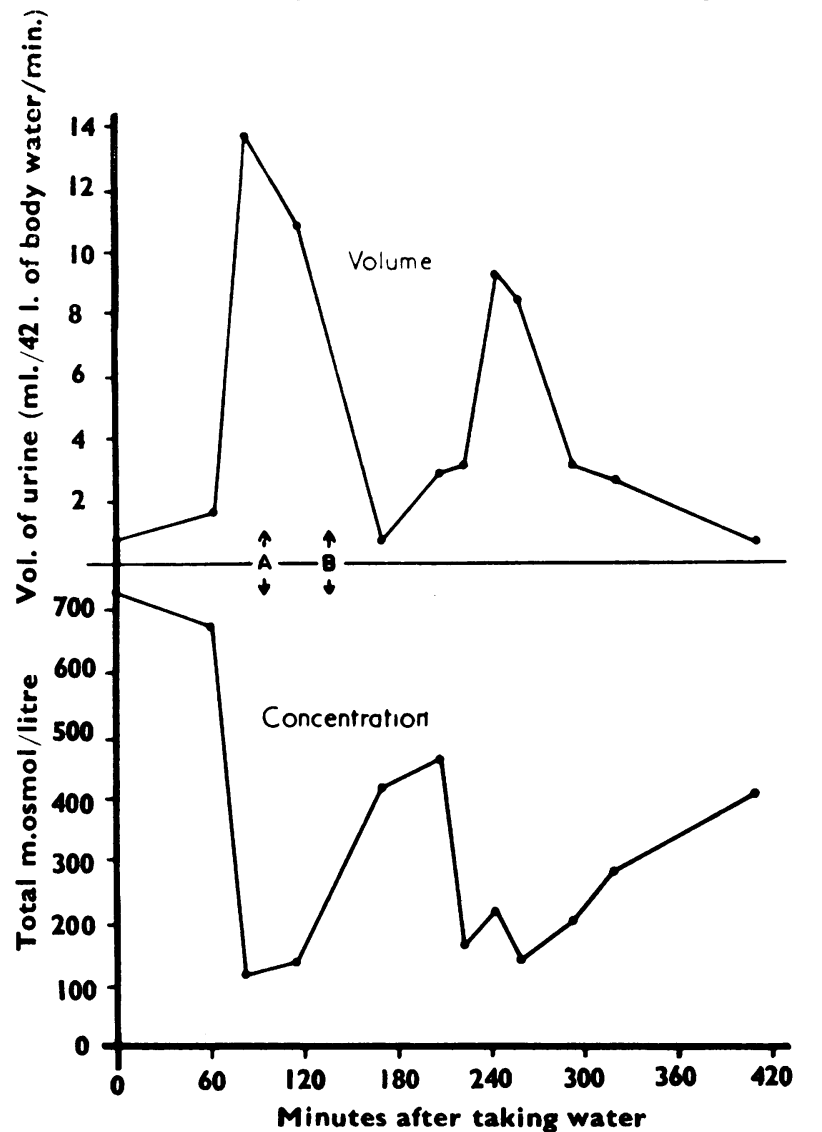

FIG. 1.-The effect of manoeuvres to withdraw blood (which involved considerable interference) on an established diuresis and on the concentration of the urine. At A no blood was obtained. At B blood was withdrawn from the femoral vein. 
the serum separated as soon as possible. The osmotic pressures of all fluids were obtained from the depression of their freezing points (Hervey, to be published; Ramsay, 1949). The factor $\frac{1000}{1 \cdot 86}$ was used to convert these results to m.osmols./1. Urea in urine and serum was determined by Lee and Widdowson's (1937) method, creatinine by a slight modification of the method described by Hawk, Oser and Summerson (1947), sodium and potassium by the Beckmann flame photometer, and chlorides after Sendroy (1937). Inulin was determined by the method described for the estimation of fructose by Bacon and Bell (1948).

The body water of the babies has been calculated by assuming that an infant weighing $2.5 \mathrm{~kg}$. contained $77 \%$ of water, one of $3.0 \mathrm{~kg} .73 \%$ and one of $3.5 \mathrm{~kg}$. $69 \%$ (Widdowson and Spray, 1951). The body of an adult weighing $70 \mathrm{~kg}$. has been assumed to contain $60 \%$ of water, i.e., 42 litres (McCance and Widdowson, 1951). The 'average' curves shown in Figs. 2 and 4 were constructed by drawing the individual curves freehand through the experimental points and taking the values at appropriate times to average for the composite curves.

\section{Results}

Fig. 2 shows the average volumes of urine passed per 421 . of body water per min. by the 10 babies and seven adults plotted against the time which had elapsed after the water had been given. This was taken as the mid-point of the period over which the dose was administered. Since Barnett et al. (1952) gave their results per $1 \cdot 73 \mathrm{sq}$. $\mathrm{m}$. per min. a curve has also been given in Fig. 2 for the volumes passed

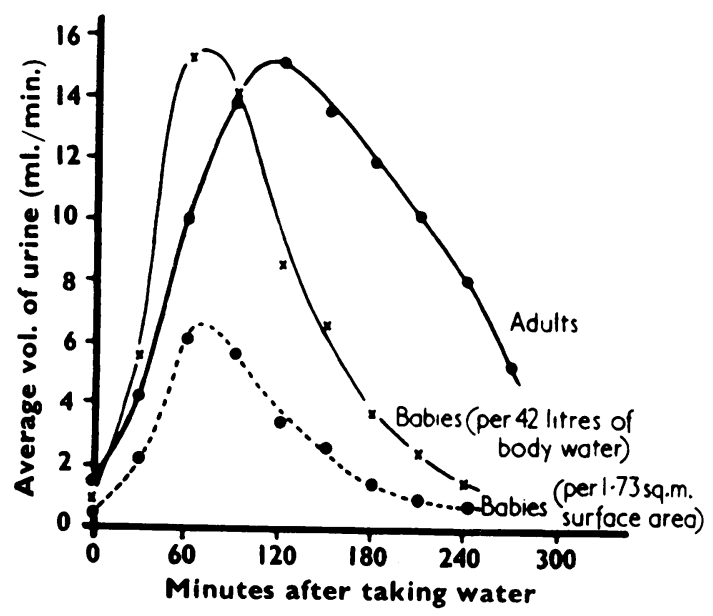

FIG. 2.-The rate of excretion of water after the administration of a dose equivalent to $6 \%$ of the weight of water in the body.

per $1 \cdot 73 \mathrm{sq}$. $\mathrm{m}$. On the basis of body water the infants excreted for a short time just as large a volume per min. as the adults and for a time did in fact excrete as large a percentage of the test dose per min. The rate of flow reached its peak in a little over an hour in the infants but not till about two hours in the adults. This difference is statistically significant but it is probably not of fundamental importance. It may have been due partly to the fact that it took slightly longer to administer the water to the adults than it did to the infants, but a more likely explanation seems to be that the dose, which was of a formidable size for adults, may have been help up longer in their stomachs (Jones, 1951). The size of the dose certainly influences the course of the diuresis, for Adolph (1943) has shown that the larger the dose the later the peak of the diuresis in adult man, and in work carried out previously (McCance, 1951), admittedly on other subjects, a much smaller dose was given and the peak of the flow came about 30 minutes earlier.

The rate of flow remained at a high level for a shorter time in the infants and had returned to its base line in four hours. The effect of this difference will be demonstrated later (Fig. 4).

Barnett et al. (1952) gave their premature babies aged 5-8 days $4 \%$ of their body weight of water, and in spite of this smaller dose obtained a diuretic response of about $7 \mathrm{ml} . / 1 \cdot 73$ sq. m./min., which must have been about the same per 421 . of body water as the one given by the present series. They gave their two adults only $2 \%$ of their body weight of water and obtained rates of urine flow of 12 to $13 \mathrm{ml} . / \mathrm{min}$. The average rate of flow obtained by McCance (1951) for adults after the administration of a dose equal to about $2 \%$ of the body water rose to $11 \mathrm{ml} . / \mathrm{min}$. The present results are in general agreement with those of Barnett et al. (1952) although the basis on which the infants were compared with the adults makes the volumes passed by Barnett's infants appear much smaller than they would have been had the comparison been made per unit of body water, and this has affected some of their conclusions and made them differ from those drawn in the present paper.

Table 1 shows the average volumes passed per minute by the adults and infants at the peak of the

TABLE 1

AVERAGE MINUTE VOLUME AND COMPOSITION OF THE URINE AT HEIGHT OF DIURESIS

\begin{tabular}{|c|c|c|c|c|c|c|c|c|c|}
\hline & & & & & & & & Adults & Infants \\
\hline \multicolumn{4}{|c|}{$\begin{array}{l}\text { Volume ml./42 litre } \\
\text { Urea (m.osmols/litre } \\
\text { Cl (m.Eq./litre) }\end{array}$} & $\begin{array}{l}\text { body } \\
\ldots \\
\ldots\end{array}$ & $\begin{array}{l}\text { wat } \\
\cdots \\
\cdots \\
\cdots\end{array}$ & $\begin{array}{c}\min . \\
\cdots \\
\cdots \\
\cdots \\
\cdots\end{array}$ & $\begin{array}{l}\cdots \\
\cdots \\
\cdots \\
\cdots\end{array}$ & $\begin{array}{r}18 \cdot 7 \\
19 \cdot 4 \\
9 \cdot 9 \\
11 \cdot 9 \\
6 \cdot 5\end{array}$ & $\begin{array}{r}20.6 \\
27.1 \\
10.4 \\
11.6 \\
6.5\end{array}$ \\
\hline \multicolumn{8}{|c|}{ Total osmolar concentration (m.osmols/litre) } & 70 & 81 \\
\hline
\end{tabular}


flow of urine. This was not necessarily always the specimen of urine in which the osmolar concentration was at its lowest, and at comparable minute volumes the osmolar concentration was sometimes higher in the infants when the rate of flow was rising than it was when it was falling. Table 1 also shows the average concentrations of urea, $\mathrm{Na}, \mathrm{K}$ and $\mathrm{Cl}$ and the total osmolarity. The urines were all very dilute and there was no significant difference between the infants and the adults. Some of the infants had higher concentrations of urea in their blood than the adults and this probably accounts for the slight difference in the concentration of urea in the urine. The infants, therefore, were able to dilute their urines as effectively as the adults. The work of Ames (1953) suggests that infants less than $\mathbf{4 8}$ hours of age would not have been able to do so. The present results are in entire agreement with those of Barnett et al. (1952) for infants of the ages studied by them and of Dicker and Heller (1951) for guinea-pigs but they differ from those of McCance and Wilkinson (1947) and of Heller (1951) for the newborn rat.

Fig. 3 shows the inulin or endogenous creatinine urine/plasma ratios of the infants from whom blood was obtained and of the adults plotted against the volume of urine passed per 421 . of body water per min., both on logarithmic scales. Similar information has been given for newborn and adult guinea-pigs during a water diuresis by Dicker and Heller (1951)

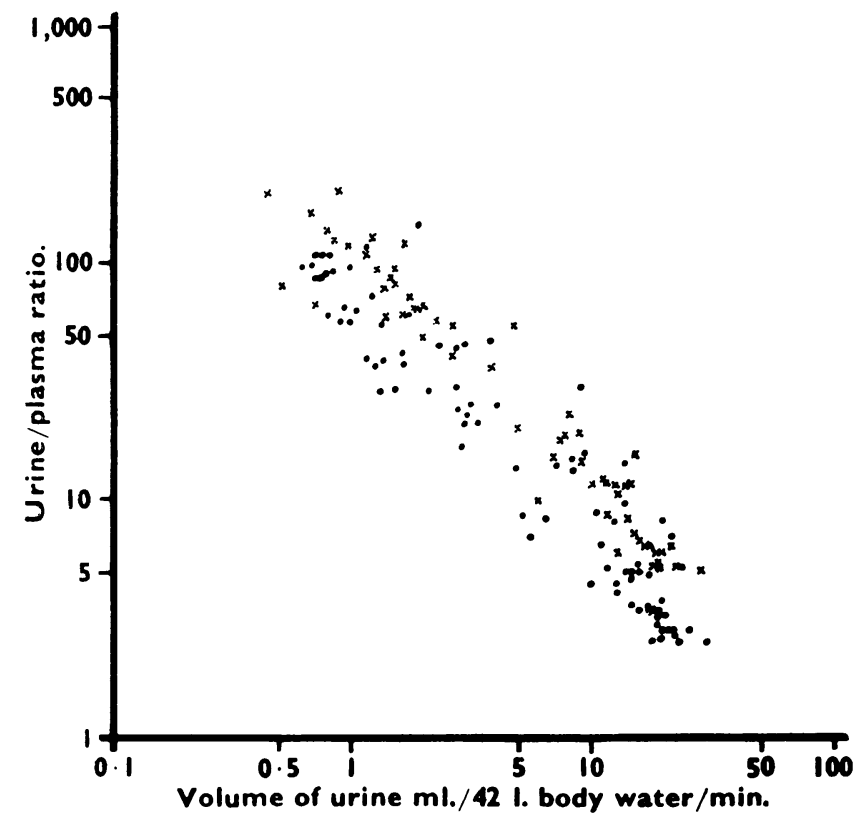

FIG. 3. - Variations of the urine/plasma ratio (inulin or endogenous creatinine) with the minute volume of the urine. $\times$ Adults. Babies. Both scales are logarithmic. and for puppies during an osmotic diuresis by Dicker (1952). The present results show that at any given minute volume the urine/plasma ratios of these infants were very little lower than those of the adults, and that they were lower by the same proportion at all minute volumes. Since the creatinine or inulin urine/plasma ratio multiplied by the minute volume is a measure of the glomerular filtration rate, these results also show that at equivalent minute volumes the glomerular filtration rates of some of the infants were a little lower than those of the adults, although others had achieved the adult values. These infants were known to be of the age when the glomerular filtration rate per $\mathbf{4 2}$ litres of body water is of the same order as that of adults (McCance and Widdowson, 1952), and had younger or older infants been studied the probability is that their urine/plasma ratios and glomerular filtration rates would have been lower or higher at all minute volumes than those given by the present series. Be that as it may, the present results show that when the disturbance to the body water of adults and of infants of these ages had been the same, the urine/plasma ratios were similar and so were the glomerular filtration rates. They do not show that urine/plasma ratios and glomerular filtration rates as high as those of adults would have been obtained in dehydrated infants for this was not investigated (Calcagno and Rubin, 1950), but they demonstrate that when water was available for excretion, the diuresis was produced in the same way by infants and by adults. In other words the infants were not achieving a diuresis by increasing their glomerular filtration rates but by decreasing the amount of water reabsorbed.

Fig. 4 shows the volume of the urine, expressed as a percentage of the water administered, passed by the end of each half-hour after the dose had been given. After one and a half hours the infants had excreted a larger percentage of the dose than the adults, and this is to be correlated with their rapid increase of urine volume shown in Fig. 2. After this time the adults continued to excrete large volumes of urine till at the end of four to four and a half hours a volume equal to that administered had been excreted. The infants' rate of excretion, however, rapidly declined (Fig. 2) with the result shown in Fig. 4. At the end of four hours the infants had only excreted a volume of 
urine equal to about $57 \%$ of the volume of water which had been administered. This is in general agreement with the results of Ames (1953) for babies of this age. Barnett et al. (1952) did not investigate this matter for they terminated

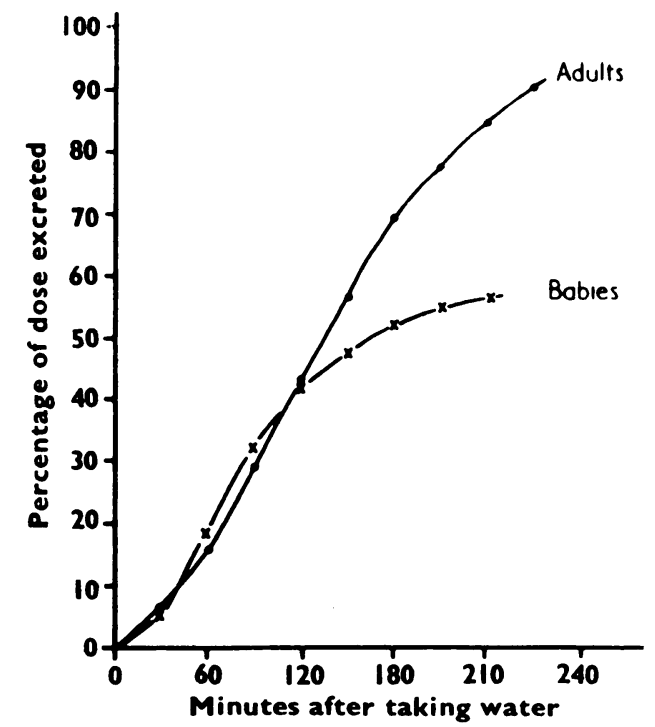

FIG. 4.-The percentage of the dose excreted after the administration of water equivalent to $6 \%$ of the weight of water in the body.

their experiments at the end of one and a half to two hours. The small volume excreted was not due to the magnitude of the extra-renal losses of water in infants, for this was measured in the same ward in 10 babies of similar age and weight and found to average $1.15 \mathrm{~g} . / \mathrm{kg} . / \mathrm{hr} . \pm 0 \cdot 57$. This would only account for $9 \%$ of the volume of water given. Hence extra-renal losses in infancy will not explain the difference between the infantile and adult response even if no allowance is made for extra-renal losses by the adults. The incomplete excretion of the test dose may have been due to the infants not being well enough hydrated at the beginning (Falk and Benjamin, 1951) but this seems improbable (Ames, 1953). This failure to restore the status quo must be regarded as a real difference between the newborn and the adult. Lasch (1923) and Ames (1953) found it in infants, Dicker and Heller (1951) in guinea-pigs and Adolph (1943) in dogs. It has also been found in rats (McCance and Wilkinson, 1947; Heller, 1951). It is to be noted that a dose of water equal to $6 \%$ of the weight of water in the body (about $150 \mathrm{ml}$. for a $3 \mathrm{~kg}$. baby) is not much greater than the volume of fluid administered in a baby's normal $4 \mathrm{oz}$. feed, and the response to water and food may be rather different from the response to water alone.

\section{Discussion}

The central matter for discussion is the extent to which infants differ from adults in their response to a large dose of water and the extent to which any conclusions about this may be influenced by the basis of comparison. The reasons for preferring a basis of body water to one of surface area have been set out by McCance and Widdowson (1952), and the present results, if they have involved minute volumes, have been compared with those of adults on the basis of body water. To show the difference, however, some of the results have also been given on the basis of surface area (see Fig. 2). At the stage of development reached by human infants at 6 to 18 days of age the administration by mouth of $6 \%$ of the weight of water in the body led to a great and rapid increase of urine flow. This flow subsided more quickly than it did in adults but on the basis of body water the minute volumes attained were the same. These infants could excrete as great a fraction of the administered water per minute as adults, and this conclusion is independent of any basis of comparison.

At the height of the diuresis the concentrations of $\mathrm{Na}, \mathrm{Cl}$ and $\mathrm{K}$ in the infants' urines were as low as they were in the adults' urines. This would probably not have been true in the first two days of life (Ames, 1953) although foetal urine characteristically has a low osmolar concentration (McCance and Widdowson 1953). Under the conditions of hydration operating in these experiments the infants did not excrete within four hours a volume of urine equal to more than $60 \%$ of the water which had been administered, whereas adults excreted a volume equal to 95 or $100 \%$. These conclusions are all independent of any basis of comparison.

At minute volumes which were equivalent on the basis of body water or of the dose of water administered, the infants had glomerular filtration rates very nearly equal to those of the adults, and they concentrated their glomerular filtrates to the same extent. Had the minute volumes of the infants been expressed per 1.73 sq. $\mathrm{m}$. of surface area each urine would have appeared to have had a minute volume less than half as great as that shown in Fig. 3. The urine/plasma ratios would not have been altered, but each would then have looked as though it corresponded to a smaller minute volume, so that at any given minute volume the urine/plasma ratios of the infants would have appeared considerably lower than those of adults. It would have followed that the infants' glomerular filtration rates were lower and that the glomerular filtrates were being less concentrated at any given minute volume (McCance and Young, 1941). It might have been 
inferred, particularly at low minute volumes, that these infants were unable to concentrate their urines to the same extent as adults. It is suggested that this would have been an unjustifiable conclusion, although it might have seemed the obvious one, and that this basis of comparison has been to some extent responsible for the view that an infant's kidney is in most respects functionally undeveloped and immature. There is no doubt that in some ways an infant's kidney is functionally immature and can be shown to be so, but the whole matter requires careful re-examination and particularly where the basis of comparison is likely to affect the conclusions. Barnett et al. (1952) found that the P/U ratio for creatinine in infants rose above the corresponding ratio in adults as the minute volumes rose to the peak of the diuresis. This may have been because their infants were given relatively much more water than their adults and so the infants' diuresis was nearer maximal than was that of the adults. There is no doubt that adults could have achieved much higher minute volumes than the work of Barnett et al. would indicate had they been given more water (see Table 1) and their urine/plasma ratios would have been correspondingly reduced.

The differences between the findings for human infants and for the newborn of other species have been outlined in presenting the results. It would appear that the human infant 6-18 days of age has a kidney which is much more mature than that of a baby or a rat 1 day old and rather more so than that of the puppy 2 days old. It seems to be comparable in development with that of the newborn guinea-pig.

It should perhaps be pointed out that the present results indicate only what the kidney does under the normal circumstances of its life. They give no indication of the diuretic responses which might be elicited after suitable pre-treatment with saline (Crawford, Schoen and Nicosia, 1952; Rosenbaum, Nelson, Strauss, Davis and Rossmeisl, 1953) or if food were to be given at the same time as the water.

The failure to excrete the whole of the test dose at the same rate as adults seems to be common to all the newborn animals so far investigated, and suggests that infants may be much more easily poisoned than adults by the continuous administration of water.

\section{Summary}

After a test dose of water equal to about $6 \%$ of the weight of water in the body, infants aged 6-18 days (1) rapidly increased their urine volumes till they were similar in magnitude to those of adults per unit of body water or per unit of water administered; (2) passed urines at the peak of the diuresis as dilute as those passed by adults; (3) did not (as adults did) excrete a volume of urine equal to that of the test dose within four to four and a half hours; (4) had glomerular filtration rates nearly equal to those of adults per unit of body water and treated the filtrate in the same way in its passage down the tubules. There was no evidence that a change in minute volume was brought about by a change in glomerular filtration rate.

The authors are indebted to Mrs. L. A. Strangeways and Miss E. Colbourn for their valuable help, and take this opportunity of expressing their appreciation of all the kindness and cooperation they have received from Dr. D. Gairdner and the staffs of the hospitals which they have visited in the course of this investigation.

\section{REFERENCES}

Adolph, E. F. (1943). Physiological Regulations. Lancaster, Pa.

Ames, R. G. (1953). Pediatrics, 12, 272.

Aschenheim, E. (1919) $Z$. Kinderheilk., 24, 281.

Bacon, J. S. D. and Bell, D. J. (1948). Biochem. J., 42, 397.

Barnett, H. L. and Vesterdal, J. (1953). J. Pediat., 42, 99.

-, McNamara, H. and Lauson, H. D. (1952). J. clin. Invest., 31, 1069.

Brod, J. (1953). Acta med. Hung., 4, 369

Calcagno, P. L. and Rubin, M. I. (1950). Amer. J. Dis. Child., 80, 514.

Crawford, J. D., Schoen, E. J. and Nicosia, A. P. (1952). Ibid., 83, 91.

Dicker, S. E. (1952). J. Physiol., 118, 384.

- and Heller, H. (1951). Ibid. $112,149$.

Falk, G. and Benjamin, J. A. (1951). Surg. Gynec. Obstet., 93, 159.

Hawk, P. B., Oser, B. L. and Summerson, W. H. (1947). Practical Physiological Chemistry, 12th ed. Philadelphia.

Heller, H. (1947). J. Physiol., 106, 245.

- (1951). Archives of Disease in Childhood, 26, 195.

Hervey, G. R. To be published.

Jones, P. E. H. (1951). J. Physiol., 113, 276

Jones, P. E. H. (1951). J. Physiol., 113, 276.

Lasch, W. (1923). Z. Kinderheilk., 36, 42.

Lee, M. H. and Widdowson, E. M. (1937). Biochem. J, 31, 2035.
McCance, R. A. (1951). Spec. Rep. med. Res. Coun., Lond. No. 275.

McCance, R. A. (1951). Spec. Rep. med. Res. Coun., Lond. No. 275. and Widdowson, E. M. (1951). Proc. roy. Soc. B., 138, 115. (1952). Lancet, 2,860 (1953). Proc. roy. Soc. B. 141, 488. and Wilkinson, E. (1947).J. Physiol., 106, 256.

and Young W. F. (1941). Ibid., 99, 265.

$\overline{M i l e s}$, B. E. and De Wardener, H. E. (1953). Lancet, 2, 539.

Ohlmann, J. (1920). Z. Kinderheilk., 26, 291.

Ramsay, J. A. (1949). J. exp. Biol., 26, 57.

Rosenbaum, J. D., Nelson, W. P. III, Strauss, M. B., Davis, R. K. and Rossmeisil, E. C. (1953). J. clin. Invest., 32, 394.

Sendroy, J. (1937). J. biol. Chem., 120, 405.

Verney, E. B. (1946). Lancet, 2, 739.

Vesterdal, J. and Tudvad, F. (1949). Acta paediat., Uppsala, 37, 429.

Vesterdal, J. and Tudvad, F. (1949). Acta paed

Widdowson, E. M. and Spray, C. M. (195i). Archives of Disease in Childhood, 26, 205. 